\title{
Diverse inhibition of plasminogen activator inhibitor type 1 by theaflavins of black tea
}

\author{
JERZY JANKUN ${ }^{1,3,4}$, MAGDALENA SKOTNICKA ${ }^{1,2}$, WIESŁAWA ŁYSIAK-SZYDŁOWSKA ${ }^{3}$, \\ ABDULRAHMAN AL-SENAIDY ${ }^{4}$ and EWA SKRZYPCZAK-JANKUN ${ }^{1}$ \\ ${ }^{1}$ Urology Research Center, Department of Urology, The University of Toledo - Health Science Campus, \\ Toledo, OH 43614, USA; Departments of ${ }^{2}$ Chemistry, Biochemistry, Ecology and Food Commodity and \\ ${ }^{3}$ Clinical Nutrition, Medical University of Gdańsk, 80-211 Gdańsk, Poland; ${ }^{4}$ Protein Research Chair, \\ Biochemistry Department, College of Sciences, King Saud University, Riyadh, Saudi Arabia
}

Received October 25, 2010; Accepted December 29, 2010

DOI: $10.3892 /$ ijmm.2011.615

\begin{abstract}
Fruits, vegetables, spices and a variety of teas are suggested for the prevention of many diseases. They encompass active, non-nutritional ingredients called nutraceuticals which are defined as food products that provide health benefits. Many nutraceuticals have been tested to identify inhibitors of plasminogen activator inhibitor (PAI-1). PAI-1 is the major and fast acting physiological inhibitor of fibrinolysis. However, preclinical studies of PAI-1 inhibitors have revealed an additional role of PAI-1 in the pathogenesis of vascular remodeling, renal injury, diabetes, obesity, Alzheimer's disease and cancer. Thus PAI-1 is a potential therapeutic target in some of these diseases. Our previous study revealed that a black tea extract (containing mostly theaflavins) inhibits PAI-1. In this study we report results for four pure $(>98 \%)$ theaflavins. Inactivation of PAI-1 was tested by clot formation and by its lysis using thromboelastometry and measurements of human plasma turbidity. Among four tested theaflavins, theaflavin-3'-gallate was the most potent in PAI-1 inhibition trailed by theaflavin-3,3'-digallate, while the other two i.e., theaflavin and theaflavin-3-gallate did not show inhibitory activity.
\end{abstract}

\section{Introduction}

Fruits, vegetables, spices and a variety of teas have been widely investigated for the prevention of many diseases because of their many non-nutritional ingredients called nutraceuticals, which are defined as food products providing health benefits.

Correspondence to: Dr Jerzy Jankun, Urology Research Center, Department of Urology, The University of Toledo - Health Science Campus, 3000 Arlington Ave., Toledo, OH 43614, USA

E-mail: jerzy.jankun@utoledo.edu

Key words: black tea, polyphenols, theaflavins, plasminogen activator inhibitor
Examples of well known nutraceuticals include: allicin (garlic), capsaicin (red chili), curcumin (turmeric), catechins (green tea), ellagic acid (pomegranate), genistein (soybean), lycopene (tomato), resveratrol (red grapes, peanuts and berries) $(1,2)$. Many nutraceuticals are strong antioxidants and are therefore, considered as possible modulators of many human diseases related to oxidative stress (for example: neurodegenerative diseases, stroke and others). However, additional mechanisms of their action include direct inhibition of enzyme activity; for example curcumin inhibits cyclooxygenases 1, 2 (COX-1, COX-2), lipoxygenase (LOX) (3) and acts on multiple cell signaling pathways $(\mathrm{NF}-\kappa \mathrm{B}, \mathrm{TNF}, \mathrm{IL}-6, \mathrm{IL}-1, \mathrm{COX}-2$ and 5-LOX) (4,5). Furthermore, nutraceuticals are usually a mixture of different chemicals, for instance curcumin contains three active major constituents (6). Others could be a mixture of derivatives and isomers and such complexity of the nutraceuticals complicates the understanding of their mechanism of action.

We have been evaluating the inhibition of plasminogen activator inhibitor type 1 (PAI-1) by nutraceuticals. PAI-1 is the major and fast acting physiological inhibitor of fibrinolysis. However, preclinical studies of PAI-1 inhibitors have revealed an additional role of PAI-1 in vascular remodeling, cancer, renal injury, diabetes, obesity and Alzheimer's disease. Inhibition of PAI-1 is a potential therapeutic target in these diseases (7-9). Since PAI-1 quickly converts itself into a latent form (PAI-1, $\mathrm{t}_{1 / 2}=2 \mathrm{~h}$ ) we have chosen its mutant with an extended half-life for this study (VLHL PAI-1, $\mathrm{t}_{1 / 2} \geq 700 \mathrm{~h}$ ) (10). Using a black tea extract containing $80 \%$ of theaflavins including theaflavin-3-3'-digallate and in smaller amounts theaflavin-3-gallate, theaflavin-3'-gallate, and theaflavin, we have found that such extract inhibits VLHL PAI-1 (11). Since it has been reported that PAI-1 is implicated in Alzheimer's disease, obesity, diabetes and others, and that drinking black tea can alleviate symptoms of these conditions, understanding which of the theaflavins inhibits PAI-1 might have profound therapeutic implications (12-15). We report that two of the studied black tea theaflavins (theaflavin-3,3'-gallate and theaflavin-3'-gallate) are good inhibitors of PAI-1 while the other two (theaflavin, theaflavin-3-gallate) are not. 

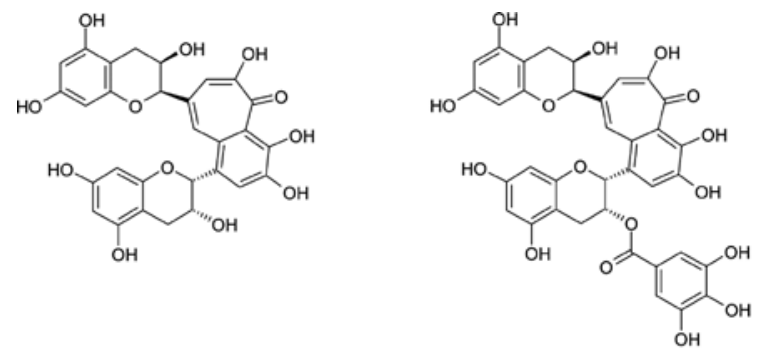

Theaflavin - TF

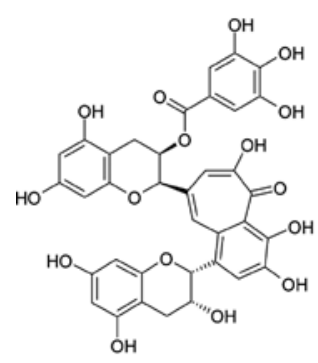

$$
\text { Theaflavin-3-gallate - TF (1) }
$$

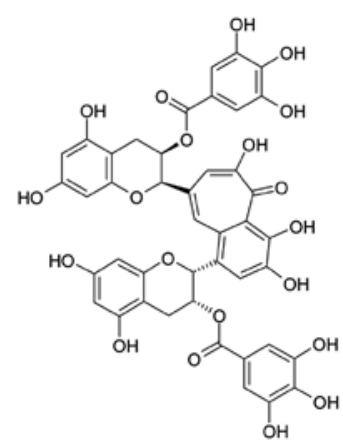

Theaflavin-3,3'-gallate - TF (2)

Figure 1. Structure of theaflavins (29).

\section{Materials and methods}

Chemicals. Theaflavin (no. F3001), theaflavin-3-gallate (no. F3002), theaflavin-3'-gallate (no. F3003), theaflavin-3-3'digallate (no. F3004) (all of $>98 \%$ purity) were purchased from PI \& PI Technology, Inc., (Guangzhou, Guangdong, China) (Fig. 1). Theaflavins were dissolved in DMSO and stored at $-20^{\circ} \mathrm{C}$.

Expression and purification of VLHL PAI-1. The mutation of two amino acids (Gln197 $\rightarrow$ Cys, Gly355 $\rightarrow$ Cys) produced VLHL PAI-1 with a very long half life $t_{1 / 2}>700 \mathrm{~h}$. To confirm the mutations, the VLHL PAI-1 DNA construct was sequenced (MWG-Biotech Inc., NC). A Baculovirus expression system was employed and purification $(+95 \%)$ of this protein was carried out as previously described (16). Aliquots of the protein were stored at $-75^{\circ} \mathrm{C}$.

Tissue plasminogen activator. Fully active human tPA (HTPA-TC) was purchased from Molecular Innovations, (Novi, MI). Protein aliquots were stored at $-75^{\circ} \mathrm{C}$. Pooled normal human sodium citrated plasma was from American Diagnostica (Stamford, CT, no. 258N) for TEG experiments, and from Helena Laboratories (Beaumont, TX, no. 5301), for spectrophotometric determination of lysis. Lyophilized plasma was stored at $4^{\circ} \mathrm{C}$, and the aliquots of plasma were reconstituted in individual vials with $1.0 \mathrm{ml}$ of deionized water before analysis. The vials were allowed to stand at room temperature with periodical swirling for 15-20 min before use.

Analysis of plasma clot formation with thromboelastography. Thromboelastography, not only allows for the measurement of a global coagulation profile, but also yields data on the kinetics

Table I. Changes of thromboelastograms and spectrograms as a function of proteolysis status.

\begin{tabular}{|c|c|c|c|c|}
\hline & Control & tPA treated & $\begin{array}{l}\text { tPA + VLHL } \\
\text { PAI-1 }\end{array}$ & $\begin{array}{c}\text { tPA + VLHL } \\
\text { PAl-1 } \\
+ \text { Inhibitor }\end{array}$ \\
\hline tPA & - & + & + & + \\
\hline VLHL PAI-1 & - & $\cdot$ & + & + \\
\hline Inhibitor & - & - & - & + \\
\hline $\begin{array}{l}\text { Expected } \\
\text { thrombo- } \\
\text { elastogram }\end{array}$ & & $\forall$ & & $\vartheta$ \\
\hline $\begin{array}{l}\text { Expected } \\
\text { Spectrogram }\end{array}$ & & & & \\
\hline
\end{tabular}

and dynamics of clot formation and clot lysis in whole blood or in plasma (17). The critical part of this instrument is a pin hanging on a torsion wire and suspended in a cup holding a sample $(360 \mu \mathrm{l})$. This pin oscillates at $6 \mathrm{rpm}$ at a $4^{\circ} 45^{\prime}$ angle at $37^{\circ} \mathrm{C}$. When plasma changes viscosity during clot formation this pin motion is progressively restrained by the clot and the cup. The strength of the clot determines the degree of the force on the pin. Sodium citrated, reconstituted plasma was used for TEG assays by mixing $1 \mathrm{ml}$ of plasma with $20 \mu \mathrm{l}$ of kaolin (Haemoscope Co., Neils, IL, USA) to which a constant amount of tPA was added [10 $\mu \mathrm{l}$ of tPA $(2.1 \mathrm{mg} / \mathrm{ml}$ in $0.4 \mathrm{M}$ HEPES, 0.1 M NaCl; pH 7.4)] as a fibrinolytic agent (18) to measure proteolysis under controlled conditions. Next, $320 \mu 1$ of the mixture was transferred to each TEG cup containing $20 \mu \mathrm{l}$ of $\mathrm{CaCl}_{2}(0.2 \mathrm{M})$ and an activity assay buffer $(50 \mathrm{mM}$ HEPES, $150 \mathrm{mM} \mathrm{NaCl}, 1 \%$ human serum albumin, $0.05 \%$ Tween-20 buffer, $\mathrm{pH}$ 6.6) with i) VLHL PAI-1 in activity assay buffer to prevent lysis by tPA, or ii) VLHL PAI-1 plus the tested compound in the same buffer to check its inhibitory action demonstrated by lysis of the clot when tPA is unopposed by PAI-1 activity (Table I and Fig. 2). The critical parameters of clotting measured by TEG are as follows: $\mathrm{R}$ is the time from the start of the reaction until a measurable clot is detected, $\mathrm{K}$ is the time from the $\mathrm{R}$ point until a certain clot firmness is achieved, An $(\alpha)$ is the maximum angle that represents kinetics of clotting and LY30 (percentage) represents clot lysis 30 min after MA (maximum amplitude) (Table II).

Analysis of plasma clot formation measured by turbidity. For plasma turbidity measurements (19) reconstituted human plasma $(1 \mathrm{ml})$ was added to a vial to which a constant amount of tPA was added [10 $\mu \mathrm{l}$ of tPA $(2.1 \mathrm{mg} / \mathrm{ml}$ in $0.4 \mathrm{M}$ HEPES, $0.1 \mathrm{M} \mathrm{NaCl} ; \mathrm{pH} 7.4)]$ as a fibrinolytic agent. The mixture was divided into two parts and the following was added to each part: i) VLHL PAI-1 to prevent lysis by tPA, or ii) VLHL PAI-1 plus tested compound to check its inhibitory action demonstrated by lysis of the clot when tPA is unopposed by PAI-1 activity. Prior to that VLHL PAI-1 was incubated for 15 min with either DMSO or different compounds in DMSO. Clot formation and dissolution was monitored at $405 \mathrm{~nm}$ every $60 \mathrm{sec}$ at $37^{\circ} \mathrm{C}$ using a spectrophotometric plate reader (Molecular Devices, Sunnyvale, CA). In this assay, clot formation is indicated by an increase in OD. Over time, the OD decreases due to clot dissolution by fibrinolytic processes, which reaches the initial OD 

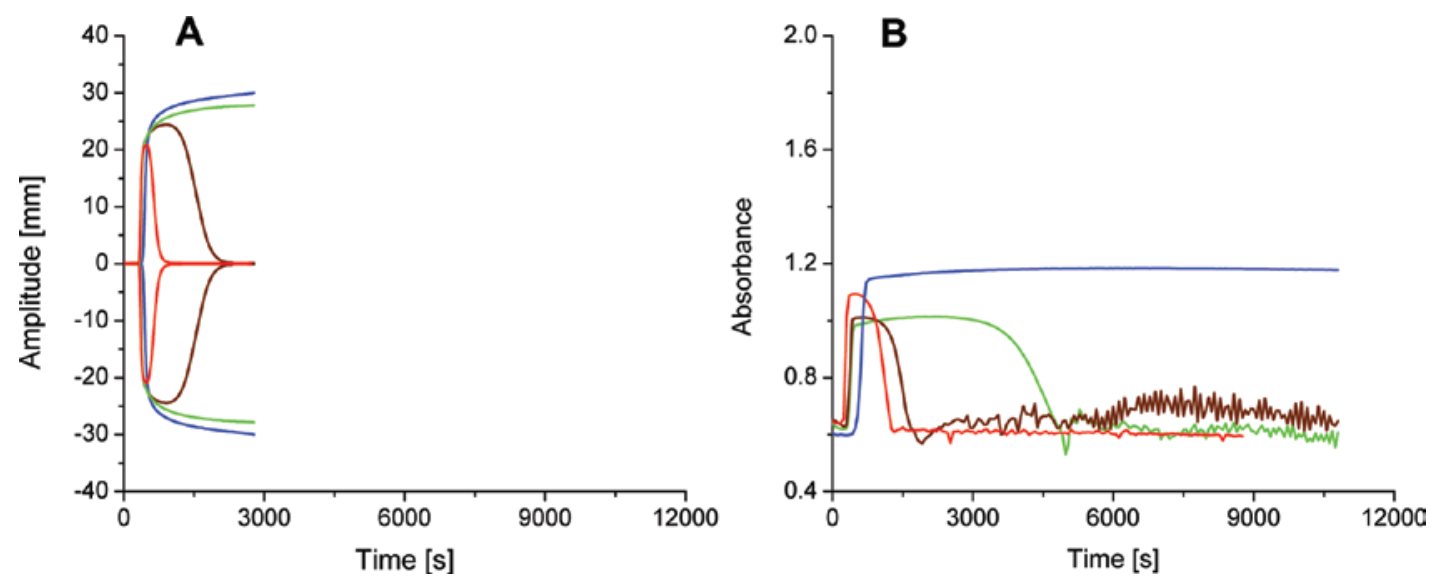

Figure 2. Example of (A) thromboelastogram and (B) turbidity, of clotted plasma not treated (control, blue); treated with tPA (red); treated with tPA and VLHL PAI-1 (green); and treated with tPA, VLHL PAI-1 and TF(1') (brown).

when the clot is completely dissolved. The critical parameters of clotting measured by this method are as follows: $\mathrm{R}_{\mathrm{T}}$ is the time from the start of the reaction until a measurable $\mathrm{OD}$ is detected, and $\mathrm{LY}_{\mathrm{T}} 30$ (percentage) represents clot lysis $30 \mathrm{~min}$ after maximum OD (Table III).

\section{Results}

Initial assessment of PAI-1 inactivation by theaflavins was done by thromboelastometry and standardized to control of pooled normal human plasma. In general we observed differences between parameters of control plasma and treated samples as can be seen in Table II. There are no normal values of TEG parameters for plasma in the literature. However, $\mathrm{R}, 120-480 \mathrm{sec}$, $\mathrm{K}, 60-180 \mathrm{sec}$; An, $55-78^{\circ} \mathrm{C}$ (this is $\alpha$-angle); MA, 51-69 $\mathrm{mm}$ and LY30, 0-8\% for blood samples are considered normal (20). Presented values in Table II for plasma are within this normal range. Only, MA was consistently lower in all plasma samples then in normal blood presumably due to an absence of platelets which are critical for clotting but absent in plasma.

Two of the black tea theaflavins inactivate PAI-1 as showed in Table II (theaflavin-3,3'-gallate and theaflavin-3'-gallate) while the other two (theaflavin, theaflavin-3-gallate) do not show inhibitory activity. Most potent was theaflavin-3'-gallate while theaflavin-3,3'-gallate was less potent.

Table II. TEG clotting parameters of control plasma and plasma treated with tPA+VLHL PAI-1 and theaflavins (N=4).

\begin{tabular}{llllll}
\hline Compound & $\mathrm{R}(\mathrm{sec})$ & $\mathrm{K}(\mathrm{sec})$ & $\mathrm{An}\left({ }^{\circ}\right)$ & $\mathrm{MA}(\mathrm{mm})$ & $\mathrm{LY} 30(\%)$ \\
\hline Control plasma & $408 \pm 6$ & $84 \pm 6$ & $70.6 \pm 0.3$ & $27.2 \pm 0.6$ & 0 \\
$\mathrm{TF} 44 \mu \mathrm{M}$ & $336 \pm 24$ & $76 \pm 6$ & $75.2 \pm 2.1$ & $25.1 \pm 0.4$ & 0 \\
$\mathrm{TF}(1) 34 \mu \mathrm{M}$ & $354 \pm 18$ & $72 \pm 12$ & $76.4 \pm 0.3$ & $26.5 \pm 1.1$ & 0 \\
$\mathrm{TF}\left(1^{\prime}\right) 34 \mu \mathrm{M}$ & $330 \pm 12$ & $72 \pm 6$ & $75.7 \pm 1.0$ & $24.3 \pm 0.6$ & $36.6 \pm 30.9$ \\
$\operatorname{TF}(2) 28 \mu \mathrm{M}$ & $348 \pm 10$ & $72 \pm 18$ & $75.7 \pm 1.0$ & $24.7 \pm 0.8$ & $30.0 \pm 21.0$ \\
\hline
\end{tabular}

Table III. Turbidity measurements of clotting parameters control plasma and plasma treated with tPA+VLHL PAI-1 and theaflavins in different concentrations $(\mathrm{N}=4)$.

\begin{tabular}{lccc}
\hline Compound & Concentration $(\mu \mathrm{M})$ & $\mathrm{R}_{\mathrm{T}}(\mathrm{sec})$ & $\mathrm{LY}_{\mathrm{T}} 30(\%)$ \\
\hline $\mathrm{TF}$ & 44 & $340 \pm 81$ & 0 \\
$\mathrm{TF}(1)$ & 34 & $360 \pm 60$ & 0 \\
$\mathrm{TF}\left(1^{\prime}\right)$ & 34 & $240 \pm 60$ & 100 \\
$\mathrm{TF}\left(1^{\prime}\right)$ & 17 & $260 \pm 80$ & 100 \\
$\mathrm{TF}\left(1^{\prime}\right)$ & 8 & $300 \pm 60$ & $64.2 \pm 2.1$ \\
$\mathrm{TF}(2)$ & 28 & $300 \pm 60$ & $46.3 \pm 5.8$ \\
$\mathrm{TF}(2)$ & 14 & $240 \pm 60$ & $13.8 \pm 3.8$ \\
$\mathrm{TF}(2)$ & 7 & $300 \pm 60$ & $1.7 \pm 0.6$ \\
\hline
\end{tabular}


Evaluation of PAI-1 inhibition was repeated by analysis of clot formation and lysis measured by turbidity. In this method comparison of $\mathrm{K}$, An and MA to TEG analysis is meaningless. However $\mathrm{R}$ and $\mathrm{R}_{\mathrm{T}}$ as well as $\mathrm{LY} 30$ and $\mathrm{LY}_{\mathrm{T}} 30$ can be judged against each other. Within experimental errors the values of $\mathrm{R}$ and $\mathrm{R}_{\mathrm{T}}$ were the same. PAI- 1 inhibition by theaflavins was similar as observed in another method, but turbidity analysis showed higher inhibitory activity of theaflavins as manifested by $\mathrm{LY}_{\mathrm{T}} 30$ values (Table III). That should not be considered as a surprise since mechanical stress on fibrin during TEG measurement confers proteolytic resistance to fibrin, which is related to poor tPA binding and penetration in the fibrin network and consequently weaker plasminogen driven proteolysis (21). The pattern of inactivation of PAI-1 by theaflavins based on turbidity measurements was the same as in the TEG method.

\section{Discussion}

Nutraceuticals including plant extracts are gaining popularity in disease prevention, but are also frequently utilized in uncontrolled therapy. For example, it is estimated that over $50 \%$ of patients diagnosed with cancer explore herbal medicine or extracts of different plants (22). Thus, understanding the possible effects of a common beverage such as black tea is important. PAI-1 could have acute effects in the management of PAI-1 affected ailments.

There is very limited literature on PAI-1 and black tea and the findings are controversial. Vorster et al investigated the antigen level of PAI-1 in a group of volunteers given 6 mugs of tea daily (23). They did not observe differences between people that drank tea and those drinking hot water. However, compliance with tea intake was measured by adding p-aminobenzoic acid to the tea bags and measuring its recovery in $24 \mathrm{~h}$ urine collections. This acid is an inhibitor of tPA and uPA and could influence measurements of PAI-1 $(23,24)$. Contrary to that Loktionov et al found that tea caused a significant decrease of PAI-1 activity in the subjects with E2/ E3 genotype (mean placebo $7.21 \mathrm{U} / \mathrm{ml}$ vs. mean tea $5.88 \mathrm{U} /$ $\mathrm{ml}, \mathrm{P}=0.007$ ) (25). ApoE has six common isoforms: $\mathrm{E} 2 / \mathrm{E} 2$, $\mathrm{E} 2 / \mathrm{E} 3, \mathrm{E} 2 / \mathrm{E} 4, \mathrm{E} 3 / \mathrm{E} 3, \mathrm{E} 3 / \mathrm{E} 4$, and E4/E4. These are products of the $\varepsilon 2, \varepsilon 3$ and $\varepsilon 4$ alleles of the ApoE gene (26). Estimated human genotype frequency of ApoE E2/E3 is in the range of $\sim 15 \%$ of the general population (26). These results provide evidence that dietary intervention may be very effective in population groups with specific genetic makeup rather than in the general population. Moreover, it is difficult to compare the effects of black tea consumption in the absence of basic information on the concentration of theaflavins in the cup, and form of the tea, for example with lemon (changes in $\mathrm{pH}$ ) or milk (high in $\mathrm{Ca}^{2+}$ ) vs. without any of them. Also, the content of total theaflavins as well as individual theaflavins can vary depending on the brand of tea and the brewing method making it difficult to draw conclusions from human studies of tea drinkers. But, assuming good bioavailability of theaflavins and conversion of other components of black tea (for instance thearubigins) to theaflavins in the acidic environment of the stomach, it is possible to reach their PAI-1 inhibitory concentration in the blood of the black tea heavy drinkers $(27,28)$. In conclusion, among four tested theaflavins theaflavin-3'-gallate and theaflavin-3,3'-gallate inhibit PAI-1 while theaflavin and theaflavin-3-gallate do not. Theaflavin-3'gallate was most potent while theaflavin-3,3'-gallate showed lower inhibitory activity.

\section{Acknowledgements}

We thank Dr R. Hart (President, PharmaIP LLC, Greenwich, CT, USA) for helpful remarks, discussions and support. This study was supported in part by grants from: PharmaIP LLC, and the Frank D. Stranahan Endowment Fund for Oncological Research.

\section{References}

1. Aggarwal BB and Shishodia S: Molecular targets of dietary agents for prevention and therapy of cancer. Biochem Pharmacol 71: 1397-1421, 2006.

2. Frank B and Gupta S: A review of antioxidants and Alzheimer's disease. Ann Clin Psychiatry 17: 269-286, 2005.

3. Jankun J, Aleem AM, Malgorzewicz S, et al: Synthetic curcuminoids modulate the arachidonic acid metabolism of human platelet 12-lipoxygenase and reduce sprout formation of human endothelial cells. Mol Cancer Ther 5: 1371-1382, 2006.

4. Agrawal DK and Mishra PK: Curcumin and its analogues: potential anticancer agents. Med Res Rev 30: 818-860, 2010.

5. Hanai $\mathrm{H}$ and Sugimoto $\mathrm{K}$ : Curcumin has bright prospects for the treatment of inflammatory bowel disease. Curr Pharm Des 15: 2087-2094, 2009.

6. Jurenka JS: Anti-inflammatory properties of curcumin, a major constituent of Curcuma longa: a review of preclinical and clinical research. Altern Med Rev 14: 141-153, 2009.

7. Brown NJ: Therapeutic potential of plasminogen activator inhibitor-1 inhibitors. Ther Adv Cardiovasc Dis 4: 315-324, 2010.

8. Van Nostrand WE and Porter M: Plasmin cleavage of the amyloid beta-protein: alteration of secondary structure and stimulation of tissue plasminogen activator activity. Biochemistry 38 : 11570-11576, 1999.

9. Wood PA: Connecting the dots: obesity, fatty acids and cancer. Lab Invest 89: 1192-1194, 2009.

10. Chorostowska-Wynimko J, Świercz R, Skrzypczak-Jankun E, Wojtowicz A, Selman SH and Jankun J: A novel form of the plasminogen activator inhibitor created by cysteine mutations extends its half-life: relevance to cancer and angiogenesis. Mol Cancer Ther 2: 19-28, 2003.

11. Skrzypczak-Jankun E and Jankun J: Theaflavin digallate inactivates plasminogen activator inhibitor: could tea help in Alzheimer's disease and obesity? Int J Mol Med 26: 45-50, 2010.

12. Bastianetto S, Yao ZX, Papadopoulos V and Quirion R: Neuroprotective effects of green and black teas and their catechin gallate esters against beta-amyloid-induced toxicity. Eur J Neurosci 23: 55-64, 2006.

13. Cesari M, Pahor M and Incalzi RA: Plasminogen activator inhibitor-1 (PAI-1): a key factor linking fibrinolysis and agerelated subclinical and clinical conditions. Cardiovasc Ther 28: 72-91, 2010.

14. Chen N, Bezzina R, Hinch E, et al: Green tea, black tea, and epigallocatechin modify body composition, improve glucose tolerance, and differentially alter metabolic gene expression in rats fed a high-fat diet. Nutr Res 29: 784-793, 2009.

15. Higgins PJ: The TGF-beta1/upstream stimulatory factorregulated PAI-1 gene: potential involvement and a therapeutic target in Alzheimer's disease. J Biomed Biotechnol 2006: $15792,2006$.

16. Jankun J, Aleem AM, Selman SH, Basrur V and SkrzypczakJankun E: VLHL plasminogen activator inhibitor spontaneously reactivates from the latent to active form. Int J Mol Med 23: 57-63, 2009.

17. Evans PA, Hawkins K, Lawrence M, Barrow MS, Williams PR and Williams RL: Studies of whole blood coagulation by oscillatory shear, thromboelastography and free oscillation rheometry. Clin Hemorheol Microcirc 38: 267-277, 2008.

18. Carr ME Jr, Krishnamurti C and Alving BM: Effect of plasminogen activator inhibitor-1 on tissue-type plasminogen activator-induced fibrinolysis. Thromb Haemost 67: 106-110, 1992. 
19. Jankun J, Aleem AM, Selman SH, et al: Highly stable plasminogen activator inhibitor type one (VLHL PAI-1) protects fibrin clots from tissue plasminogen activator-mediated fibrinolysis. Int J Mol Med 20: 683-687, 2007.

20. TEG 5000 User's Manual Version 4.2 Software. Haemoscope Corporation, 2006.

21. Kolev K, Varju I, Szabo L, Machovich R, Silva M and Longstaff C: Hampered dissolution of fibrin formed under mechanical stress. J Thromb Haemost 8: 44, 2010.

22. Boon $\mathrm{H}$ and Wong $\mathrm{J}$ : Botanical medicine and cancer: a review of the safety and efficacy. Expert Opin Pharmacother 5: 2485-2501, 2004

23. Vorster H, Jerling J, Oosthuizen W, et al: Tea drinking and haemostasis: a randomized, placebo-controlled, crossover study in free-living subjects. Haemostasis 26: 58-64, 1996.

24. Świercz R, Skrzypczak-Jankun E, Merrell MM, Selman SH and Jankun J: Angiostatic activity of synthetic inhibitors of urokinase type plasminogen activator. Oncol Rep 6: 523-526, 1999.
25. Loktionov A, Bingham SA, Vorster H, Jerling JC, Runswick SA and Cummings $\mathrm{JH}$ : Apolipoprotein E genotype modulates the effect of black tea drinking on blood lipids and blood coagulation factors: a pilot study. Br J Nutr 79: 133-139, 1998.

26. Hill JM, Bhattacharjee PS and Neumann DM: Apolipoprotein $E$ alleles can contribute to the pathogenesis of numerous clinical conditions including HSV-1 corneal disease. Exp Eye Res 84: 801-811, 2007.

27. Crozier A, Jaganath IB and Clifford MN: Dietary phenolics: chemistry, bioavailability and effects on health. Nat Prod Rep 26: 1001-1043, 2009.

28. Rechner AR, Wagner E, Van Buren L, Van De Put F, Wiseman S and Rice-Evans CA: Black tea represents a major source of dietary phenolics among regular tea drinkers. Free Radic Res 36: $1127-1135,2002$.

29. Kuroda Y and Hara Y: Antimutagenic and anticarcinogenic activity of tea polyphenols. Mutat Res 436: 69-97, 1999. 